\title{
A survey of the training needs of PCDs in the GDS
}

\author{
The workforce of professionals complementary to dentistry in the general dental services: a survey of general \\ dental practices in the South West A. Sprod and J. Boyles Br Dent J 2003; 194: 389-397
}

\section{Objective}

To describe the working patterns, training experiences, estimated size, and future training needs of the workforce of professionals complementary to dentistry in the general dental service in an English region.

\section{Methods}

Postal questionnaire of NHS dental practices in the South West of England.

\section{Results}

The response rate was 65\%. There was an average of two whole time equivalent (wte) dentists working per practice. Dentists work a mean 0.8 wte per practice. Sixty per cent of practice time is NHS. Vacancies existed for 120 dentists (98 wte) with reported difficulties in recruitment. There was an average of 1.25 wte dental nurses per dentist with $44 \%$ of nurses working part-time. A quarter of nurses' time is on non-clinical duties. The turnover rate for nurses was between 13\% and 26\%, with recruitment difficulties. Approximately 50\% of nurses do not have a professional qualification. There is variation between health authorities in proportions of qualified nurses. Hygienists are employed in $72 \%$ of practices, but only $20 \%$ of their work is NHS. Dentists have favourable attitudes to an expansion in the employment and training of professionals complementary to dentistry.

\section{Conclusions}

There are problems with recruitment and retention of all categories of the dental workforce in the GDS, particularly in rural areas. There is a large unmet need for pre- and post-qualification training for professionals complementary to dentistry compounded by marked inequalities in access to training.

\section{IN BRIEF}

- This is a postal questionnaire survey of the working patterns of professionals complementary to dentistry (PCDs) in general dental practices in the South West of England.

- The numbers, working patterns and training experiences of PCDs are described.

- The high vacancy and turnover rates for PCDs point to problems of recruitment and retention.

- The majority of dentists hold favourable attitudes to increasing the training and use of PCDs.

- An estimate is made for the future training needs of PCDs.

\section{COMMENT}

This paper is both interesting and timely, not so much in what it tells us, although it does make good reading, but in what it tells us we do not know.

My interest in workforce planning has been increased and multiplied by the stories I hear whenever I speak to a group of practitioners at a BDA Section or Branch meeting or at a Section 63 event. No matter where I may be in the UK, the story is always the same - no dentists to be had and not enough trained support personnel. This enormous problem is compounded by the bizarre and haphazard arrangements for dental nurse training. The imminent registration requirement for dental nurses is going to aim a searchlight at that problem and the picture will not be a healthy one.

Not enough dentists, not enough hygienists and not enough nurses.

This sad state of affairs has been slowly deteriorating since the dental workforce was last investigated in 1987. How things have changed since then. The latest dental workforce review for England is due to be published in the Spring of 2003 but it has been hampered by the fact there are no national data on working dentists or their essential support workers, the PCDs. Scotland has made strenuous efforts to get a grip on its workforce problems via a major programme of data collection. An excellent piece of work was carried out in the Midlands recently and now we have a sound piece of work from the South West, but where is the national data?

If plans are to be made to identify, train and employ the right numbers of people to deliver a dental service (whether it is provided inside the NHS or in the private sector) we must know how many of each category we need. In order to do the number crunching around that problem we need to establish the baseline where are we starting from?

This paper is valuable indeed but we must remain vigilant. There must be no chance of data collection being done on a piecemeal basis, leaving us with a data set for the South West that is incompatible with that produced in the North East. We need a UKwide approach to dental human resource data that is robust, repeatable and relevant.

John Renshaw, general dental practitioner, Scarborough. 